\title{
Mini Inferior Turbinoplasty-Tunneling Technique Versus Conventional Partial Inferior Turbinectomy in Adults: A Comparative Study
}

Original
Article

\author{
Essam A. Abo Elmagd, Mahmoud S. Khalifa, Bishoy E. Wahba, Abdelrahman A. \\ El Tahan
}

Department of Otorhinolaryngology, Faculty of Medicine, Aswan University, Egypt.

\section{ABSTRACT}

Background: Inferior turbinate reduction is a well-described procedure performed whenever medical treatment for patients with hypertrophic inferior turbinates or vasomotor rhinitis fails. There are several techniques of turbinate reduction that include turbinectomy, submucous diathermy, inferior turbinoplasty, cryotherapy, CO2 laser turbinoplasty, Coblation channelling and others. Each technique is associated with its own short-term and long-term complications such as bleeding, crusting and recurring of the turbinate hypertrophy.

Materials and Methods: We studied 80 patients attending the ENT department outpatients at Aswan university hospital from June 2018 to June 2019. All patients were clinically and radiologically diagnosed with bilateral inferior turbinate hypertrophy without response to medical treatment. Patients were randomized to two groups: Group A patients that underwent Mini turbinoplasty using tunnelling techniques and Group B patients that had conventional partial inferior turbinectomy Technique.

Results: The intraoperative time was longer in group A patients who had turbinoplasty-tunneling technique compared to group B who had conventional partial turbinectomy. However, intraoperative blood loss and nasal Packing were required mostly in group B patients. Postoperative bleeding and crustations were significantly higher in group B patients. There was no significant difference regarding the percentage synechia between both groups. Nasal obstruction symptom markedly improved in group B patients.

Conclusion: The current study revealed that Conventional Partial Inferior Turbinectomy is better than Mini Inferior Turbinoplasty Tunneling Technique regarding relief of symptoms of nasal obstruction.

Key Words: Bleeding, Micro-debrider, partial turbinectomy, turbinoplasty.

Received: 28 July 2020, Accepted: 21 August 2020

Corresponding Author: Essam A. Abo Elmagd, MD, Assistant professor, Department of Otolaryngology-Head and Neck Surgery, Aswan University, Egypt, Tel.: 01003406024, E-mail: esamali801@yahoo.com

ISSN: 2090-0740, November 2020 Vol.21, No.3

\section{INTRODUCTION}

The inferior turbinate is a key structure serving a vital role in nasal physiology. However, inferior turbinate hypertrophy can lead to decreased nasal airflow and a sense of nasal obstruction. Chronic nasal obstruction can substantially affect quality of life, productivity, and work especially when medical therapies fail, so surgical management is often recommended. ${ }^{[5-11]}$

Inferior turbinate reduction is a well-described procedure performed whenever medical treatment for patients with hypertrophic inferior turbinates or vasomotor rhinitis fails. There are several techniques of turbinate reduction that include turbinectomy, submucous diathermy, inferior turbinoplasty, cryotherapy, CO2 laser turbinoplasty, Coblation channelling and others. Each technique is associated with its own short-term and longterm complications such as bleeding, crusting and recurring of the turbinate hypertrophy. ${ }^{[5-7]}$
A microdebrider allows us to effectively remove the bone and soft tissue because its rotation motor can be connected to different types of dissectors and drills. In addition, this tool enables us to obtain excellent surgical visualization because its attached aspirator absorbs the resected material along with any blood, keeping the site free of debris. Further-more, Microdebriders help to reduce adjacent tissue damage because there are refrigerants perfused within the protection tube. ${ }^{[13]}$

Techniques for inferior turbinate reduction vary with various surgical methods, which differ in the approach of preservation of tissue from total turbinectomy to limited submucosal cauterization. ${ }^{[6]}$

\section{PATIENTS AND METHODS:}

We studied 80 patients attending the ENT department outpatients at Aswan university hospital from June 2018 to June 2019. All patients were clinically and radiologically 
diagnosed with bilateral inferior turbinate hypertrophy without response to medical treatment. Patients were randomized to two groups: Group A patients that underwent Mini turbinoplasty using tunnelling techniques and Group B patients that had conventional partial inferior turbinectomy Technique.

\section{Group A: Mini Inferior Turbinoplasty-tunneling Technique}

Mini inferior turbinoplasty-tunneling technique was performed under general anesthesia. This procedure was performed under 0-degree endoscopic guidance. An infiltration of the inferior turbinate with normal saline was done. After lateralization of the inferior turbinate by freer elevator. A microdebrider was used for Mini inferior turbinoplasty-tunneling technique. After creating an anteroinferior submucosal pocket on the inferior turbinate with a conventional 15 blade, The KARL STORZ microdebrider unit was set at speed of 5000:7000 cps on oscillating mode. The inferior turbinate size was reduced with an inferior turbinate $2.9-\mathrm{mm}$ blade especially from the anterior head, taking great care to stay in the submucosal plane. The patients with no complications were discharged after 24 hours.

\section{Group B: Conventional Partial Inferior Turbinectomy}

Conventional partial inferior turbinectomy was performed under general anesthesia. This procedure was performed under 0-degree endoscopic guidance. after lateralization of the inferior turbinate by freer elevator, the Heyman scissor was used to remove the hypertrophied part of the inferior turbinate then anterior nasal packing was applied for 48hours for haemostatis.

\section{Both groups were compared accordingly:}

\section{1) Intra-operatively to evaluate:}

a) Amount of blood loss measured as estimated blood loss in $\mathrm{ml}$.

b) The duration of procedure from the beginning of the surgery to the end of the surgery using stopwatch.

c) The need for nasal packing after end of operation to stop bleeding and we used vaseline gauze soaked in panthenol cream.

\section{2) Post-operatively along follow up visits as} regard:

a) Presence or absence of blood clots that were suctioned and cleaned along first week visit.

b) Presence or absence of synechia along second week visit. c) Presence or absence nasal symptoms along third visit one month after the surgery.

d) Last visit after 3 months to check if there is recurrence or not.

\section{RESULTS:}

Eighty patients were enrolled in this study, 38 were males and 42 were females they were divided into two groups: group A: (40) patient (22 males and 18 females) underwent Mini Inferior Turbinoplasty-tunneling Technique and group B: (40) patient (16 male and 24 female) had Conventional Partial Inferior Turbinectomy.

The intraoperative time was longer in group A patients who had turbinoplasty-tunneling technique compared to group B who had conventional partial turbinectomy (Table 1). However, intraoperative blood loss was noted more in group B patients. (Table 2) Nasal Packing was required mostly in group B patients. (Table 3 ) Postoperative bleeding and crustations were significantly problematic in group B patients. (Tables 4 and 5) There was no statistically significant difference regarding the percentage synechia between both groups. (Table 6). Nasal obstruction symptom markedly improved in group B patients. (Table 7).

Table 1: Comparison between the two groups as regards time of surgery

\begin{tabular}{ccc}
\hline Time of surgery (min.) & Group A & Group B \\
\hline Mean & 20.71 & 12.03 \\
SD & 5.44 & 2.82 \\
Median & 20.00 & 9.00 \\
Minimum & 15.00 & 5.00 \\
Maximum & 35.00 & 15.00 \\
P value & \multicolumn{2}{c}{} \\
\hline
\end{tabular}

Significant $\quad P$ value is $<0.001$

Time of surgery is longer in group A than group B.

Table 2: Comparison between the two groups as regards intraoperative blood loss

\begin{tabular}{ccc}
\hline Bleeding (intra-operative) $\mathrm{ml}$ & Group A & Group B \\
\hline Mean & 20.71 & 12.03 \\
SD & 5.44 & 2.82 \\
Median & 20.00 & 9.00 \\
Minimum & 15.00 & 5.00 \\
Maximum & 35.00 & 15.00 \\
P value & $<0.001$ \\
\hline \multirow{2}{*}{$P$ value is $<0.001$} \\
Significant \\
Intra-operative blood loss is more in group B than group A.
\end{tabular}


Table 3: Comparison between the two groups as regards nasal packing.

\begin{tabular}{ccccccc}
\hline \multicolumn{2}{c}{$\begin{array}{c}\text { Clinical } \\
\text { characteristics }\end{array}$} & \multicolumn{2}{c}{ Group A } & \multicolumn{2}{c}{ Group B } & count \\
\hline $\begin{array}{c}\text { Nasal } \\
\text { pack }\end{array}$ & Yes & count & 6 & $15 \%$ & 40 & $100 \%$ \\
\hline
\end{tabular}

Significant Pvalue is 0.031

Nasal packing is needed more in group B than in group A.

Table 4: Comparison between the two groups as regards post-operative bleeding

\begin{tabular}{|c|c|c|c|c|c|c|}
\hline \multirow{2}{*}{\multicolumn{2}{|c|}{$\begin{array}{c}\text { Clinical } \\
\text { characteristics }\end{array}$}} & \multicolumn{2}{|c|}{ Group A } & \multicolumn{2}{|c|}{ Group B } & \multirow{2}{*}{$P$ value } \\
\hline & & count & $\%$ & count & $\%$ & \\
\hline \multirow{2}{*}{ Bleeding } & Yes & 2 & $5 \%$ & 24 & $60 \%$ & \multirow{2}{*}{$<0.001$} \\
\hline & No & 38 & $95 \%$ & 12 & $40 \%$ & \\
\hline
\end{tabular}

Significant $P$ value is $<0.001$

Bleeding post-operative is more in group B than group A.

Table 5: Comparison between the two groups as regards post-operative crustations

\begin{tabular}{ccccccc}
\hline \multicolumn{2}{c}{$\begin{array}{c}\text { Clinical } \\
\text { characteristics }\end{array}$} & Group A & \multicolumn{2}{c}{ Group B } & count & value \\
\hline $\begin{array}{c}\text { post-operative } \\
\text { crustation }\end{array}$ & Yes & count & 4 & $10 \%$ & 40 & $100 \%$ \\
\hline
\end{tabular}

Significant $P$ value is $<0.001$

Post-operative crustation is significantly more in group B than group A.

Table 6: Comparison between the two groups as regards post-operative synechia

\begin{tabular}{|c|c|c|c|c|c|c|}
\hline \multirow{2}{*}{\multicolumn{2}{|c|}{$\begin{array}{c}\text { Clinical } \\
\text { characteristics }\end{array}$}} & \multicolumn{2}{|c|}{ Group A } & \multicolumn{2}{|c|}{ Group B } & \multirow{2}{*}{ Pvalue } \\
\hline & & count & $\%$ & count & $\%$ & \\
\hline \multirow{2}{*}{ Adhesions } & Yes & 4 & $10 \%$ & 8 & $20 \%$ & \multirow{2}{*}{0.259} \\
\hline & No & 36 & $90 \%$ & 32 & $80 \%$ & \\
\hline
\end{tabular}

Non-Significant $P$ value is 0.259

No significant difference between both groups as regard post-operative synechia.

Table 7: Comparison between the two groups as regards relief of symptom

\begin{tabular}{cccccc}
\hline \multicolumn{2}{c}{$\begin{array}{c}\text { Clinical } \\
\text { characteristics }\end{array}$} & Group A & \multicolumn{2}{c}{ Group B } & count \\
\hline \multirow{2}{*}{$\begin{array}{c}\text { relief of } \\
\text { symptom }\end{array}$} & Yes & 25 & $62.5 \%$ & 35 & $87.5 \%$ \\
\hline
\end{tabular}

Significant $\quad P$ value is $<0.001$

Relieve of symptom is better in group B than group A.

\section{DISCUSSION}

Hypertrophy of the inferior turbinates is a common cause of nasal obstruction and thus, it is frequently seen in the ear, noses, and throat field. In most cases it can successfully be treated with topical steroids and/or antihistamines. However, some patients are refractory to medical therapy. Proper history taking and clinical assessment is essential before proceeding to turbinate surgery.
Since the early $1900 \mathrm{~s}$, the inferior turbinates have been subjected to surgical manipulation to solve the problem of nasal obstruction and thereby to improve breathing. Given the important role in the physiology of the nasal turbinate, both for the dynamic ventilator and for the important functions of the covering mucosa.

Chronic nasal obstruction can substantially affect quality of life, productivity, and finances, and when medical therapies fail, surgical management is often 
recommended. Many techniques for inferior turbinate reduction exist, including outfracturing, submucosal soft tissue reduction (ie, electrocautery, radiofrequency coblation, and powered microdebrider turbinoplasty), submucosal bone removal, laser reduction, partial turbinectomy, and total turbinectomy.

During the last decade, a number of techniques for turbinate reduction have been described. No technique is perfect, and each is associated with known short- and long-term complications. The goal of the surgical treatment should be to diminish complaints while preserving functions and optimizing volume reduction together. The aim of our study is to assess the effectiveness of mini inferior turbinoplasty-tunneling technique compared to conventional partial inferior turbinectomy in adults. We included 80 patients in the study with typical history of nasal obstruction caused by inferior turbinate hypertrophy, not responding to medical treatment. Patients were divided into two groups; each underwent a method of turbinate reduction (group A: Mini Inferior Turbinoplasty Tunneling Technique and group B: Conventional Partial Inferior Turbinectomy).

Results showed the duration of surgery was significantly longer in group A (Mini inferior turbinoplasty tunneling technique) than group B (Conventional partial inferior turbinectomy), the mean time in group A was 20.7 minutes and in group B was 12 minutes.

In agreement with another study which concluded that the average time of surgery in Conventional Partial Inferior Turbinectomy was 11.1 minutes as the same in the present study. ${ }^{[2]}$

While another study reported that the average time in Mini inferior turbinoplasty tunneling technique was 12 minutes. ${ }^{[9]}$

Bleeding intra-operatively was significantly more in group B (Conventional partial inferior turbinectomy) than group A (Mini inferior turbinoplasty tunneling technique), the average in group B was $63 \mathrm{ml}$ while in group A was $19 \mathrm{ml}$.

In a study on 90 patients showed that the bleeding intra-operatively was $22 \mathrm{ml}$ in Mini Inferior Turbinoplasty Tunneling Technique which are near to the results in this study. ${ }^{[3]}$

In contrast another study showed that the bleeding intra-operatively in Mini Inferior Turbinoplasty Tunneling Technique was $45 \mathrm{ml}$ in average. ${ }^{[2]}$

Also another study reported that the average intraoperative bleeding in Mini Inferior Turbinoplasty Tunneling Technique was $50 \mathrm{ml} .^{[8]}$
In this study, there is significantly difference in the need for nasal packing post-operatively, in group B (100\%) more than group A (15\%), and this made good relation between bleeding intra-operatively and post-operative nasal packing. Which made the need of post-operative nasal pack more in cases with a lot of intra-operative bleeding.

In agreement with another study which concluded that about $90 \%$ of patients who do Conventional Partial Inferior Turbinectomy needed nasal packing for $48 \mathrm{hrs}$ post-operative to stop bleeding. ${ }^{[2]}$

Also another study reported that no need for anterior nasal packing after Mini Inferior Turbinoplasty Tunneling Technique. ${ }^{[9]}$

There was significant difference between the two groups in the present study according to post-operative bleeding, in group A (Mini inferior turbinoplasty tunneling technique) was $5 \%$ and in group B (Conventional partial inferior turbinectomy) was 60\%.

In agreement with another study which concluded that about $7 \%$ of patient who do Mini inferior turbinoplasty tunneling technique suffered from postoperative bleeding which were near to the results in this study. ${ }^{[9]}$

Also another study reported that about 55\% of patient who had Conventional partial inferior turbinectomy suffered from post-operative bleeding which were near to the results in this study. ${ }^{[8]}$

There was significant difference between the two groups in the present study according to post-operative crustation which were more in group B (Conventional partial inferior turbinectomy) than group A (Mini inferior turbinoplasty tunneling technique).

In agreement with another study which concluded that post-operative crustation in Mini inferior turbinoplasty tunneling technique less than in Conventional partial inferior turbinectomy. ${ }^{[9]}$

Also another study reported that there were severe crustation after Conventional partial inferior turbinectomy that need more time to relief. ${ }^{[12]}$

There was no significant difference between the two groups in the present study according to postoperative synechia, which were $10 \%$ in group A (Mini inferior turbinoplasty tunneling technique) and $20 \%$ in group B (Conventional partial inferior turbinectomy).

However, another study reported that the intranasal adhesion formation after Conventional Partial Inferior Turbinectomy were $9.5 \% .^{[12]}$ 
While another study reported that the intranasal adhesion formation after Mini Inferior Turbinoplasty Tunneling Technique were $9.6 \%$. As in the present study. ${ }^{[2]}$

There was marked improvement in nasal obstruction in both groups and it was more in group $\mathrm{B}$ than group $\mathrm{A}$ in the present study. Which were $62.5 \%$ one month post-operatively in Mini Inferior Turbinoplasty Tunneling Technique and $87.5 \%$ one month post-operatively in Conventional Partial Inferior Turbinectomy.

In agreement with another study which concluded that the typical symptoms related to nasal obstruction were significantly reduced from 1 month after surgery in Mini Inferior Turbinoplasty Tunneling Technique. Which were $65 \%$ one month post-operatively. ${ }^{[1]}$

Also another study reported the relief of nasal obstruction post-operatively in Conventional Partial Inferior Turbinectomy were $88 \%$ one month after surgery which are similar in this study. ${ }^{[4]}$

While another study reported the typical symptoms related to nasal obstruction were significantly reduced from 1 months after surgery in Mini Inferior Turbinoplasty Tunneling Technique. Which were 90\% one month post-operatively. All the subjective nasal symptoms were lower. ${ }^{[10]}$

\section{CONCLUSION}

The current study revealed that Conventional Partial Inferior Turbinectomy is better than Mini Inferior Turbinoplasty Tunneling Technique regarding time of surgery and relief of symptoms. However Mini Inferior Turbinoplasty Tunneling Technique is better than Conventional Partial Inferior Turbinectomy regarding intra-operative bleeding, post-operative bleeding, post-operative crustation and post-operative nasal packing.

\section{ETHICAL}

The name of ethics committee: ethics committee, Faculty of Medicine, Aswan University (IRB NO: 0000775834(Expire August-7-2020)

Consent to participate was waived by an IRB (ethics committee, Faculty of Medicine, Aswan University) as is deemed unnecessary according to national regulations.

\section{CONFLICT OF INTEREST}

There are no conflicts of interest.

\section{REFERENCES}

1. Chen YL, Liu CM, Huang HM. Comparison of microdebrider-assisted inferior turbinoplasty and submucosal resection for children with hypertrophic inferior turbinates. Int $\mathrm{J}$ Pediatr Otorhinolaryngol 2007;71:921-927

2. El Henawi D, Ahmer MR, Madian YT. Comparison between power-assisted turbinoplasty and partial inferior turbinectomy in the treatment of inferior turbinate hypertrophy. ORL J Otorhinolaryngol Relat Spec. 2011;73:151-155.

3. Fradis, Milo, et al. Effect of submucosal powered turbinoplasty in chronic nasal obstruction due to turbinate enlargement. American journal of otolaryngology, 2002, 23.6: 332-336.

4. Gomaa M. A., et al. Comparative study between partial surgical inferior turbinectomy and sub-mucosal diathermy of inferior turbinate for treatment of inferior turbinate hypertrophy. Otolaryngology, 2015, 5.217: 2 .

5. Hol MK, Huizing EH (2000) Treatment of inferior turbinate pathology: a review and critical evaluation of the different techniques. Rhinology 38:157-166.

6. Juniper EF: Impact of upper respiratory allergic diseases on quality of life. JAllergy ClinImmunol 101 (2Pt2):S386-S391, 1998.

7. Larrabee YC, Kacker A (2014) Which inferior turbinate reduction technique best decreases nasal obstruction? Laryngoscope 124(4):814-815.

8. Lorenz, K. J.; MAIER, H. Shaver-Turbinoplastik Microdebrider-assisted inferior turbinoplasty. HNO, 2013, 61.3: 240-249.

9. Nagalingeswaran, Ahilasamy, and Rajendran Dinesh Kumar. Mini Inferior Turbinoplasty-Tunneling Technique.Indian Journal of Otolaryngology and Head \&amp; Neck Surgery, vol. 70, no. 4, 2018, pp. 604"C606., doi:10.1007/s12070-018-1292-9.

10. Romano, Antonio, et al. Comparative study between partial inferior turbinotomy and microdebriderassisted inferior turbinoplasty. Journal of Craniofacial Surgery, 2015, 26.3: e235-e238.

11. Scheithauer MO: Surgery of the turbinates and "emptynose" syndrome. GMS Curr Top Otorhinolaryngol Head Neck Surg9. [Doc03], 2010. 
12. White, A.; Murray, J. A. M. Intranasal adhesion formation following surgery for chronic nasal obstruction. Clinical Otolaryngology \& Allied Sciences, 1988, 13.2: 139-143.
13. YOON S., YOON Y. and LEE S.: Clinical Results of Endoscopic Dacryocystorhinostomy using a Microdebrid-er. Korean Journal of Ophthalmology, 20 (1): 1-6, 2006. 